\title{
PERAN PASIEN DAN KELUARGA DALAM UPAYA PENCEGAHAN BAHAYA DAN ADVERSE EVENT DI RUMAH SAKIT Natalia Cristianti P Marbun
}

\author{
Email : christiantinatalia72@gmail.com
}

\section{LATAR BELAKANG}

Pelayanan keperawatan merupakan cerminan utama dari keberhasilan suatu pelayanan kesehatan. Pelayanan kesehatan mengutamakan keselamatan pasien. Keselamatan adalah kebutuhan dasar manusia dan kebutuhan prioritas kedua setelah kebutuhan fisiologis pada hierarki kebutuhan yang harus terpenuhi . Perkembangan ilmu pengetahuan dan tekhnologi yang sedemikian pesat menyebabkan pelayanan kesehatan di rumah sakit menjadi sangat kompleks sehingga jika tidak dilakukan dengan benar dan hati-hati akan berpotensi untuk terjadinya Insiden Keselamatan Pasien (IKP) yang terdiri dari Kejadian Tidak Diharapkan (KTD), Kejadian Nyaris Cedera (KNC), Kejadian Tidak Cedera (KTC) dan Kondisi Potensial Cedera (KPC) (Depkes,2006). Permasalahan keselamatan pasien di rumah sakit merupakan masalah yang memerlukan penanganan segera karena dapat mengakibatkan cedera langsung pada pasien.

Keluarga merupakan unit paling dekat dengan pasien, dan merupakan perawat utama bagi pasien. Keluarga berperan dalam menentukan cara atau perawatan yang diperlukan pasien di rumah sakit. Keberhasilan perawat di rumah sakit akan sia sia jika tidak dibantu dengan keluarga yang berperan sebagai partner pelayanan kesehatan. Peran serta keluarga sejak awal perawatan di rumah sakit akan berpengaruh terhadap keadaan pasien. Maka dari itu sangat diperlukan peran keluarga sebagai partner bagi pelayanan kesehatan.

Keselamatan pasien merupakan prioritas utama untuk dilaksanakan terkait dengan isu mutu dan citra perumahsakitan. Keselamatan pasien merupakan sebuah prioritas utama yang harus diprogramkan dan dilaksanakan oleh rumah sakit, yang bertujuan untuk melindungi pasien dari setiap kejadian tak terduga yang tak diharapkan. Gerakan (Patient Safety) keselamatan pasien telah menjadi spirit dalam pelayanan rumah sakit seluruh dunia tidak hanya rumah sakit di negara maju yang menerapkan keselamatan pasien untuk menjamin mutu pelayanan, tetapi juga 
rumah sakit di negara berkembang seperti di Indonesia. Kementerian Kesehatan Republik Indonesia telah mengeluarkan Peraturan Menteri Kesehatan No. 11 Tahun 2017 tentang Keselamatan Pasien di Rumah Sakit. Peraturan ini menjadi tonggak utama operasionalisasi keselamatan pasien di rumah sakit seluruh Indonesia. Banyak rumah sakit di Indonesia yang telah berupaya membangun dan mengembangkan keselamatan pasien, namun upaya tersebut dilaksanakan berdasarkan pemahaman manajemen terhadap keselamatan pasien. Peraturan menteri ini memberikan panduan bagi manajemen rumah sakit agar dapat menjalankan spirit keselamatan pasien secara utuh. Keselamatan Pasien adalah suatu sistem yang membuat asuhan pasien lebih aman, meliputi assesment risiko, identifikasi dan pengelolaan risiko pasien, pelaporan dan analisis insiden, kemampuan belajar dari insiden dan tindak lanjutnya, serta implementasi solusi untuk meminimalkan timbulnya risiko dan mencegah terjadinya cedera yang disebabkan oleh kesalahan akibat melaksanakan suatu tindakan atau tidak mengambil tindakan yang seharusnya diambil (Permenkes, 2011)

\section{METODE}

Metode yang digunakan dalam jurnal dengan bahan kajian Peran Pasien dan Keluarga dalam Upaya Pencegahan Bahaya dan Adverse Event di Rumah Sakit ini menggunakan metode tersearch atau pengumpulan data dengan menggunakan beberapa literature review seperti teks buku,referensi jurnal,ebook dengan menganalisis dan membaca setiap sumber literature berkenaan dengan topik materi yang sedang dibahas untuk mendapatkan berbagai informasi yang lengkap dan akurat dengan cara menyimpulkannya dari literature review yang ada. Sumbersumber yang dibaca dan dicari penulis juga berkenaan dengan materi permasalahan yang akan dibahas oleh penulis agar sistematis dan berkaitan sehingga mempermudah pemahaman pembaca.

\section{HASIL}

Peran keluarga sesuai dengan tugas-tugas keluarga dalam bidang kesehatan salah satunya adalah memberikan perawatan kepada anggota keluarga yang sakit dan yang tidak dapat membantu dirinya sendiri karena cacat atau usia terlalu muda. Peran keluarga tersebut meliputi 
mengingatkan/memonitor waktu minum obat, mengontrol persediaan obat, mengantarkan penderita kontrol, memisahkan alat-alat penderita dengan anggota keluarga lain, meningkatkan kesehatan lingkungan penderita, dan pemenuhan kebutuhan psikologis agar penderita tidak merasa terisolir dalam lingkungannya

Keselamatan pasien (patient safety) adalah suatu sistem dimana rumah sakit membuat asuhan pasien lebih aman dalam upaya mencegah terjadinya cidera yang disebabkan oleh kesalahan akibat melaksanakan suatu tindakan atau tidak mengambil tindakan yang seharusnya diambil.Menurut Komite Keselamatan Pasien Rumah Sakit tahun 2008, keselamatan pasien adalah kondisi pasien bebas dari cedera yang tidak seharusnya terjadi yang masih bisa dihindari atau bebas dari risiko dan cidera yang berpotensial akan terjadi.2 Berdasarkan Peraturan Menteri Kesehatan Republik Indonesia Nomor 11 Tahun 2017, keselamatan pasien merupakan suatu sistem yang membuat asuhan pasien lebih aman, meliputi asesmen risiko, identifikasi dan pengelolaan risiko pada pasien, pelaporan dan analisis insiden, kemampuan belajar dari insiden dan tindak lanjutnya, serta implementasi solusi untuk meminimalkan timbulnya risiko dan juga mencegah terjadinya cidera yang disebabkan kesalahan akibat melaksanakan suatu tindakan atau tidak mengambil tindakan yang seharusnya diambil.

Tujuan sistim keselamatan pasien adalah sebagai berikut:

a) Menciptakan budaya keselamatan pasien di rumah sakit

b) Meningkatkan akuntabilitas rumah sakit terhadap pasien dan masyarakat

c) Menurunkan kejadian tidak diharapkan (KTD) di rumah sakit

d) Melakukan pencegahan sehingga tidak akan terjadi kejadian yang tidak diharapkan

Jenis insiden dapat dibagi sebagai berikut:

a. Kejadian tidak diharapkan (KTD) Suatu kejadian yang mengakibatkan cedera yang tidak diharapkan pada pasien karena suatu tindakan atau karena tidak bertindak, bukan karena underlying disease atau kondisi pasien.

b. Kejadian nyaris cedera (KNC) Suatu Insiden yang belum sampai terpapar ke pasien sehingga tidak menyebabkan cedera pada pasien. 
c. Kejadian tidak cedera (KTC) Insiden yang sudah terpapar ke pasien, tetapi tidak menimbulkan cedera, dapat terjadi karena keberuntungan.

d. Kondisi potensial cedera (KPC) Kondisi yang sangat berpotensi untuk menimbulkan cedera, tetapi belum terjadi insiden.

e. Kejadian sentinel Suatu KTD yang mengakibatkan kematian atau cedera yang serius.

Standar keselamatan pasien rumah sakit di Indonesia mengacu pada Hospital Patient Safety Standard yang dikeluarkan oleh Joint Commmision on Acreditation of Health Organizations Illnois tahun 2002, yang diselaraskan dengan situasi dan kondisi yang terjadi di Indonesia. Standar keselamatan pasien terdiri dari 7 standar yaitu sebagai berikut :
a. Hak pasien
b. Mendidik pasien dan keluarga
c. Keselamatan pasien dan kesinambungan pelayanan

d. Penggunaan metode-metode peningkatan kinerja untuk melakukan evaluasi dan program peningkatan keselamatan pasien.

e. Peran kepemimpinan dalam meningkatkan keselamatan pasien

f. Mendidik staf tentang keselamatan pasien

g. Komunikasi merupakan kunci bagi staf untuk mencapai keselamatan pasien

\section{PEMBAHASAN}

Keselamatan pasien sebagai suatu sistem memberikan asuhan kepada pasien lebih aman, mencegah cedera akibat kesalahan karena melakukan tindakan atau tidak melakukan tindakan yang seharusnya dilakukan. Insiden keselamatan pasien meliputi kesalahan medis (medical errors), kejadian yang tidak diharapkan (adverse event), dan nyaris terjadi (near miss). Undangundang Nomor 44 Tahun 2009 tentang Rumah Sakit bertujuan memberikan perlindungan kepada 
pasien, masyarakat, dan sumber daya manusia, mempertahankan dan meningkatkan mutu pelayanan rumah sakit, serta memberi kepastian hukum kepada masyarakat dan rumah sakit.

Adverse Event atau Kejadian Tidak Diharapkan (KTD) merupakan suatu kejadian yang mengakibatkan cedera yang tidak diharapkan pada pasien karena suatu tindakan (commission) atau tidak mengambil tindakan yang seharusnya diambil (omission), dan bukan karena "underlying disease" atau kondisi pasien. Kesalahan tersebut bisa terjadi dalam tahap diagnostik seperti kesalahan atau keterlambatan diagnosa, tidak menerapkan pemeriksaan yang sesuai, menggunakan cara pemeriksaan yang sudah tidak dipakai atau tidak bertindak atas hasil pemeriksaan atau observasi.

Keluarga merupakan bagian dari tim pengobatan dan perawatan. Maka, peran keluarga penting untuk memantau kebutuhan pasien dari laporan perawat atau jika perlu malakukan komunikasi langsung. Keluarga merupakan sistem pendukung pertama dan utama bagi individu. Dukungan keluarga yang baik bisa menjadi sumber motivasi, semangat dan perlindungan terhadap resikoresiko bahaya kepada pasien.

Keselamatan pasien (patient safety) adalah suatu sistem dimana rumah sakit membuat asuhan pasien lebih aman dalam upaya mencegah terjadinya cidera yang disebabkan oleh kesalahan akibat melaksanakan suatu tindakan atau tidak mengambil tindakan yang seharusnya diambil. Peran keluarga dalam menjaga keselamatan pasien dipelayanan kesehatan yaitu:

1. Memberikan informasi yang benar, jelas, lengkap dan jujur tentang pasien

2. Mengetahui dan melaksanakan kewajiban serta tanggung jawab pasien maupun keluarga

3. Mengajukan pertanyaan-pertanyaan untuk hal yang tidak dimengerti kepada tenaga kesehatan 4. Memahami dan menerima konsekuensi pelayanan kesehatan

5. Mematuhi dan menghormati peraturan rumah sakit

6. Memperlihatkan sikap menghormati dan tenggang rasa dalam proses bersama tim kesehatan mengelola pasien

7. Memenuhi kewajiban finansial yang telah disepakati. 
Adapun penerapan enam sasaran keselamatan pasien dan peran keluarga dalam menjaga keselamatan pasien di pelayanan kesehatan yaitu:

1) Ketepatan Identifikasi Pasien Pasien dalam keadaan tidak sadar, gelisah, mengalami gangguan penglihatan, gangguan pendengaran, gangguan proses pikir, mendapat obat bius, atau gangguan lain tidak mampu melakukan identifikasi diri dengan benar. Selain itu pasien yang pindah ruang rawat atau bertukar tempat tidur saat perawatan di rumah sakit berisiko mengalami ketidaktepatan identifikasi, maka rumah sakit menyusun sistem untuk memastikan identifikasi pasien sebagai individu yang akan menerima pelayanan adalah tepat dan jenis pelayanan atau pengobatan terhadap individu tersebut adalah sesuai. Peran pasien dan keluarga untuk memastikan ketepatan identifikasi pasien adalah:

a. Memberikan data diri yang tepat pada saat mendaftar sesuai dokumen data diri yang dimiliki.

b. Selama rawat inap pasien dipakaikan gelang. Pasien dan keluarga harus memahami fungsi gelang dan patuh menggunakan gelang tersebut selama rawat inap karena gelang tersebut dipakai oleh tim kesehatan guna memastikan kebenaran identitas dan faktor risiko pasien saat memberikan pelayanan.

c. Pasien atau keluarga kooperatif saat dilakukan verifikasi identitas oleh petugas saat akan melakukan tindakan, memberikan obat, mengambil preparat untuk pemeriksaan laboratorium dan lain-lain

2) Komunikasi Efektif Pasien yang menjalani rawat inap dikelola oleh dokter dan berbagai profesi lain sebagai tim dengan menerapkan sistem komunikasi yang efektif untuk memberikan pelayanan. Peran pasien dan keluarga mewujudkan komunikasi efektif adalah:

a. Menunjuk atau menetapkan anggota keluarga yang diberi kewenangan untuk berkomunikasi dengan tim kesehatan. Penunjukkan ini diperlukan untuk memastikan komunikasi berlangsung efektif dan berkesinambungan, tidak mengalami rantai komunikasi yang panjang dan kompleks yang berisiko menyebabkan perubahan makna isi informasi.

b. Memberikan informasi dan data terkait kondisi pasien kepada tim kesehatan dengan benar dan jelas. 
c. Memberikan informasi pada tenaga kesehatan bila ada kejadian tidak diharapkan.

d. Meminta informasi yang diperlukan kepada tim kesehatan

3) Pemberian Obat secara Aman Pemberian obat merupakan bagian yang mengambil porsi dominan dalam tata kelola pasien rawat inap. Peran serta keluarga dalam menjamin keamanan pemberian obat adalah:

a. Memberikan informasi yang lengkap tentang riwayat obat yang pernah dikonsumsi sebelum masuk rumah sakit

b. Memberikan informasi tentang riwayat alergi atau reaksi yang dialami saat menggunakan obat tertentu

c. Mendukung pengawasan pemberian obat selama rawat inap dengan cara memastikan identitas pasien benar, menanyakan jenis obat yang diberikan, tujuan pemberian, dosis dan waktu pemberian obat.

4) Kepastian Tepat-Lokasi, Tepat-Prosedur, Tepat-Pasien Operasi Salah satu prosedur yang dilakukan sebelum tindakan operasi adalah proses verifikasi. Peran pasien dan keluarga dalam proses verifikasi praoperasi adalah memberikan informasi yang benar dan bekerja sama secara kooperatif. Proses yang dilakukan meliputi:

a. Verifikasi lokasi, prosedur, dan pasien yang benar. Proses ini dilakukan dengan membuat tanda pada lokasi yang dioperasi. Penandaan lokasi operasi ini melibatkan pasien, dibuat oleh dokter yang akan melakukan tindakan dan dilaksanakan saat pasien dalam keadaan sadar. Tanda ini tidak boleh dihapus dan harus terlihat sampai saat akan disayat

b. Memastikan bahwa semua dokumen, foto, hasil pemeriksaan yang relevan tersedia, diberi label dengan baik

c. Melakukan verifikasi ketersediaan peralatan khusus yang dibutuhkan.

5) Pengurangan risiko infeksi terkait pelayanan kesehatan Rumah sakit merupakan tempat yang memungkinkan berkumpulnya berbagai jenis kuman sedangkan pasien yang sedang dirawat memiliki daya tahan tubuh relatif rendah. Dengan demikian diperlukan suatu proses bersama untuk mencegah timbulnya infeksi lain yang tidak berhubungan dengan penyakit utama pasien. Peran pasien dan keluarga dalam pengurangan risiko terkait pelayanan kesehatan adalah: 
a. Menerapkan prosedur cuci tangan yang benar Keluarga memiliki kemungkinan sering kontak dengan pasien, maka untuk melindungi diri sendiri dan melindungi pasien dari perpindahan kuman disarankan keluarga menerapkan prosedur cuci tangan yang benar pada 5 momen yaitu saat sebelum kontak dengan pasien, sesudah kontak pasien, sesudah ke toilet, sebelum dan sesudah makan. Lingkungan sekitar pasien berisiko terpapar kuman maka disarankan untuk mencuci tangan sesudah kontak dengan lingkungan pasien (meja, alat tenun, tempat tidur dsb). Guna memperoleh hasil cuci tangan yang optimal, pasien dan keluarga disarankan mencermati dan mengikuti petunjuk 6 langkah mencuci tangan yang diberikan oleh petugas kesehatan atau panduan cuci tangan yang ada di rumah sakit.

b. Membatasi pengunjung pasien Selama pasien dirawat di rumah sakit, hendaknya pasien tidak berinteraksi dengan banyak orang karena berisiko terpapar kuman dari pengunjung dalam keadaan pertahanan diri yang relatif rendah, dengan demikian peran keluarga diperlukan untuk membatasi pengunjung yang kontak dengan pasien

c. Menerapkan etika batuk yang benar Keluarga dan pengunjung yang batuk berisiko menyebarkan kuman melalui partikel halus di udara, dengan demikian bila sedang mengalami batuk keluarga perlu menggunakan masker atau menerapkan tehnik perlindungan yang benar saat batuk yaitu menutup mulut dan hidung menggunakan lengan.

6) Pengurangan Risiko Pasien Jatuh Individu yang sedang sakit memiliki keterbatasan dalam pengamanan diri termasuk menghindari jatuh. Rumah sakit mengambil tindakan untuk mengurangi risiko dengan melakukan pengkajian faktor-faktor yang dapat menyebabkan jatuh, seperti penggunaan obat, gaya jalan dan keseimbangan, alat bantu berjalan yang digunakan oleh pasien, riwayat jatuh saat berjalan atau saat istirahat baring di tempat tidur. Peran pasien dan keluarga dalam mencegah pasien jatuh saat dirawat di rumah sakit adalah:

a. Memastikan bahwa penanda pasien beresiko jatuh berupa gelang kuning dipakai pasien

b. Jangan melepas atau memindah kartu kuning yang dipasang petugas kesehatan dekat tempat tidur pasien atau di depan kamar pasien karena kartu tersebut merupakan penanda untuk mewaspadai pasien yang beresiko jatuh 
c. Keluarga atau pasien perlu memastikan diri untuk memahami informasi yang diberikan oleh petugas kesehatan agar dapat mendukung tindakan pencegahan jatuh. Adapun informasi yang perlu diketahui adalah faktor resiko jatuh yang teridentifikasi seperti obat yang dipergunakan, kesadaran pasien, keseimbangan saat berjalan, dll, tindakan pencegahan jatuh yang perlu dilakukan, cara untuk minta bantuan, cara menggunakan bel atau sarana komunikasi di ruangan, cara mengatur pengamanan tempat tidur, pengggunaan tali pengaman, dll.

\section{PENUTUP}

Keselamatan pasien sebagai suatu sistem diharapkan memberikan asuhan kepada pasien lebih aman, mencegah cedera akibat kesalahan karena melakukan tindakan atau tidak melakukan tindakan yang seharusnya dilakukan. Sistem tersebut meliputi penilaian risiko, identifikasi pasien, resiko pasien terjatuh, pengelolaan hal yang berhubungan dengan pasien koma, pelaporan dan analisis accident, kemampuan belajar dari accident dan tindak lanjutnya serta implementasi solusi untuk meminimalkan timbulnya risiko. Keselamatan pasien adalah suatu sistem yang membuat asuhan keperawatan terhadap pasien menjadi lebih aman. Perawat merupakan salah satu sumber daya manusia yang sangat dibutuhkan untuk mencapai kinerja yang optimal. Berdasarkan hal tersebut, penerapan pasien safety oleh perawat sangat penting dalam upaya mengurangi insiden kecelakaan kerja pada pasien. Selain dari peran perawat untuk mencegah adanya bahaya atau KTD,peran keluarga juga sangat penting dalam hal ini.

Selain dokter dan perawat, pasien ataupun keluarga sebagai partner di pelayanan kesehatan juga memiliki peran yang sangat penting dalam upaya mencegah bahaya dan kejadian tidak diharapkan untuk menjaga keselamatan pasien. Pasien dan keluarga diharapkan dapat memberikan informasi yang benar, jelas, lengkap dan jujur tentang pasien dan mematuhi seluruh aturan yang ada di rumah sakit..Kepedulian keluarga sebagai upaya pencegah bahaya ditunjukkan melalui fungsi afektif dan perawatan kesehatan keluarga. Menurut Friedman et al. (2003) fungsi afektif berbasis pada kepedulian keluarga terhadap kebutuhan sosioemosional semua anggota keluarganya. Hasil penelitian kepedulian keluarga dilakukan dengan memotivasi, menjadi pendengar yang baik, membuat senang, memberi kesempatan rekreasi, memberikan tanggung jawab, dan kewajiban peran dari keluarga sebagai pemberi asuhan. Hal ini didukung 
penelitian Soekarta (2004), menyediakan waktu untuk berkomunikasi, sering berbincangbincang, bercanda, mengadakan rekreasi bersama dapat meringankan beban psikologis. Keluarga berkomitmen dalam memberikan dukungan dan mendampingi pasien untuk patuh dalam pengobatan.

\section{DAFTAR PUSTAKA}

Darliana,D.(2016). HUBUNGAN PENGETAHUAN PERAWAT DENGAN UPAYA PENERAPAN PATIENT SAFETY DI RUANG RAWAT INAP RUMAH SAKIT UMUM DAERAH DR. ZAINOEL ABIDIN BANDA ACEH. Idea Nursing Journal, 7 (1)

Febrina,W.,Rahmi,A.(2018). ANALISIS PERAN KELUARGA SEBAGAI PENGAWAS MINUM OBAT (PMO) PASIEN TB PARU. Jurnal Human Care, 3(2). 118-129

Fitriana,Y.,Pratiwi,K.(2018). PELAKSANAAN PATIENT SAFETY DI RUMAH SAKIT UMUM DAERAH DAN RUMAH SAKIT UMUM SWASTA BANTUL BERDASARKAN KETENTUAN UNDANG-UNDANG NOMOR 44 TAHUN 2009 TENTANG RUMAH SAKIT. Jurnal Kebidanan, 7 (1), 28-39

Herawati,Y,T. (2015). BUDAYA KESELAMATAN PASIEN DI RUANG RAWAT INAP RUMAH SAKIT X KABUPATEN JEMBER. Jurnal IKESMA, 11(1)

Juniarti,N,H., Mudayana,A,A.(2018). PENERAPAN STANDAR KESELAMATAN PASIEN DI RUMAH SAKIT UMUM DAERAH PROVINSI NUSA TENGGARA BARAT. Jurnal Kesehatan Poltekkes Ternate, 11(2), 93 - 108

Lombogia,A.,Rottie J.,\& Karundeng,M. (2016). HUBUNGAN PERILAKU DENGAN KEMAMPUAN PERAWAT DALAM MELAKSANAKAN KESELAMATAN PASIEN (PATIENT SAFETY) DI RUANG AKUT INSTALASI GAWAT DARURAT RSUP PROF. DR. R. D. KANDOU MANADO. e-journal Keperawatan (e-Kp), 4(2)

Simamora, R. H. (2019). Buku ajar pelaksanaan identifikasi pasien. Uwais Inspirasi Indonesia.

Salawati,L. (2020). PENERAPAN KESELAMATAN PASIEN RUMAH SAKIT. Jurnal Averrous, 6 (1) 
Tutiany,Lindawati,\&Krisanti,P. MANAJEMEN KESELAMATAN PASIEN,Pusdik SDM Kesehatan. 2017

Utarini,A.,Djasr,H. (2012). KESELAMATAN PASIEN DAN MUTU PELAYANAN KESEHATAN: MENUJU KEMANA?. Jurnal Manajemen Pelayanan Kesehatan, 15(4)

Wuryaningsih,E,W., Hamid,A,Y,S.,\& Helena,N. (2013). STUDI FENOMENOLOGI: PENGALAMAN KELUARGA MENCEGAH KEKAMBUHAN PERILAKU KEKERASAN PASIEN PASCA HOSPITALISASI RSJ. Jurnal Keperawatan Jiwa . 1(2). 178-185

Yusuf,M. (2017). Penerapan Patient Safety Di Ruang Rawat Inap Rumah Sakit Umum Daerah Dr. Zainoel Abidin. Jurnal Ilmu Keperawatan 5(1) 